\title{
Fixed Prosthesis in Missing Maxillary First Molar Among Medium Aged Adult: A Retrospective Study
}

\author{
Pooja Umaiyal' ${ }^{1}$ M, V.Ashok* and Jaiganesh Ramamurthy² \\ ${ }^{1}$ Saveetha Dental College and Hospitals, Saveetha Institute of Medical \\ and Technical Sciences, Chennai, India. \\ *Department of Prosthodontics, Saveetha Dental College and Hospitals, Saveetha \\ Institute of Medical and Technical Sciences, Chennai, India. \\ ${ }^{2}$ Department of Periodontics, Saveetha Dental College and Hospitals, Saveetha Institute \\ of Medical and Technical Sciences, Chennai, India. \\ Corresponding author email: ashok@saveetha.com
}

\begin{abstract}
Loss of maxillary molar can have negative impact on functional, psychological and social consequences. Study of this along with the knowledge of these causes can reduce the number of patients involved in losing molars due to lack of awareness and lack of regular dental visits. The aim of this study was to educate and evaluate the incidence of fixed partial dentures as the treatment opted by the patient with missing maxillary first molar, among the age group of 35-50 years. Patients included in this retrospective study were those who reported to Saveetha Dental College and Hospitals with missing maxillary first molar. The data was collected from patient records dated from June 2019 to march 2020 and analysed. The collected data was tabulated and analysed using SPSS software. Among 177 patients, $69.2 \%$ were females and $30.8 \%$ were males. Highest prevalence of loss of maxillary first molar was among the age group of 35-43 years. Majority were edentulous with a single missing maxillary first molar $36.7 \%$. Among all, $35.9 \%$ of the participants opted and had fixed partial denture as the prosthesis for the edentulous space. The incidence of tooth loss among male and females was due to their socio-economic status and lack of awareness on oral hygiene and regular dental visits. This demonstrates the need of preventive programs in order to control the cause like dental caries and to provide education for oral health. Hence, the results of this study must be interpreted within the limitations of this study and further cohort studies must be done including larger data. Such study should also include certain other parameters like the reasons for extraction, the patients' socio-economic status and their diet.
\end{abstract}

KEY WORDS: EDENTATIONS, FIXED PARTIAL DENTURE, MEDIUM AGED ADULTS, MISSING MAXILLARY FIRST MOLAR.

\section{INTRODUCTION}

The first tooth to develop among permanent dentition is the first molar, its development is initiated at birth and at the age of 6-7 years, the first molar erupts into the oral cavity. During this period the first molar becomes the last tooth in the arch and its dexterity for maintenance of oral hygiene becomes difficult due to the limited accessibility. Moreover,

Biosc Biotech Res Comm P-ISSN: 0974-6455 E-ISSN: 2321-4007

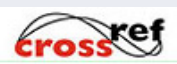

Identifiers and Pagination

Year: 2021 Vol: 14 No (10) Special Issue

Pages: $01-06$

This is an open access article under Creative

Commons License Attribn 4.0 Intl (CC-BY).

DOI: $h t t p: / / d x . d o i . o r g / 10.21786 / b b r c / 14.10 .1$ the morphology of the first molar includes deep pits and fissures which makes it more prone for food lodgement, this in turn leads to dental caries (Hegde and Ragavendran, 2012). Dental caries is a multifactorial disease of the tooth. It is influenced by various factors like the microorganisms, teeth morphology, saliva and also our current lifestyle. There are numerous factors that influence dental caries like the environmental factors, social factors and the cultural factors (Jyothi et al., 2017; Kannan and Venugopalan, 2018; Ariga et al., 2018; Scrascia et al., 2020; Lacarbonara et al., 2021).

The appearance of dental caries is highly correlated with the cariogenic diet of ours and the access to dental care. The incidence of periodontal disease and caries that affect the molar can differ by age, gender, education, dental health issues or habits, and access to professional care among different social groups. The main predictors of tooth missing
Article Information

Received: $05^{\text {th }}$ Aug 2021

Accepted after revision: $10^{\text {th }}$ Oct 2021 
are caries and periodontitis. And the negligence towards the treatment of initial stage of periodontitis or dental caries and lack of awareness in retaining the teeth after symptomatic pulp involvement leads to loss of the teeth. Numerous studies have been conducted on the various causes of permanent tooth extraction among children, adolescents and adults in industrialized countries (Angelillo, Nobile and Pavia, 1996; Haddad et al., 1999; Çağlaroğlu et al., 2008; Artun and Thalib, 2011; Rezaie et al., 2018; Scrascia et al., 2020; Cimõeset al., 2021) .

Loss of first permanent molars can negatively affect both arches. As the first molar is said to be the key of occlusion, its loss also results in reduced masticatory efficiency and leads to supra eruption of opposing teeth over a time period, causing migration of adjacent teeth and occlusal disharmony. Understanding the aetiology of tooth loss in a population is important in conducting dental health programs for preventive measures and an awareness of the required prosthesis or the replacement of the missing tooth is also necessary. Various treatment options are available for the replacement of the missing tooth or for the closure of space created. Fixed partial denture (FPD) is commonly used in a situation where the second or third molar is present. But some of the drawbacks of Fixed partial denture include hypersensitivity on improper fixation, chances of caries on abutments, loss of adjacent tooth structures of tooth preparation, eventually leading sensitivity of that adjacent tooth structure and also food lodgement beneath improperly fabricated pontics. A better option of treatment is a prosthetic implant but the success of it is hindered by peri-implantitis (Ganapathy et al., 2016; Ganapathy et al., 2017; Kannan and Venugopalan, 2018; Duraisamy et al., 2019; Scrascia et al., 2020; Fareen et al., 2021).

Previously our team has a rich experience in working on various research projects across multiple disciplines (Gheena and Ezhilarasan, 2019; Ke et al., 2019; Malli Sureshbabu et al., 2019; Mehta et al., 2019; Samuel et al., 2019; Sharma et al., 2019; Varghese et al., 2019; Venu et 1., 2019; Venu et al., 2019; Vignesh et al., 2019; Jain et al., 2019; Jose et al., 2020; Krishnaswamy et al., 2020; Muthukrishnan et al., 2020; Samuel et al., 2020; Sathish and Karthick, 2020). Now the growing trend in this area motivated us to pursue this project. The idea for this study stemmed from the current interest in our community. With this in mind, the aim of this study was to evaluate the incidence of fixed partial denture as the treatment opted by the patients with missing maxillary first molar.

\section{MATERIAL AND METHODS}

A retrospective study was conducted in a university setting at Saveetha Dental College and Hospitals. The advantage of conducting this study in a university setting was the availability of data from the patient records with the involvement of both the genders. The unavailability of location specific data was the disadvantage of this study. Ethical approval for conducting the study was obtained from the Institutional Scientific Review Board, Saveetha Dental College and Hospitals. Data collected for this study was from the patient who had visited the institution for treatment from June 2019 till March 2020. Out of 86000 patients reported during this period, a total of 117 patients who have to undergo prosthetic treatment for missing maxillary first molar were collected. The sampling bias for the study was minimised by including data of all the patients among the age group of 35 to 50 years who had missing maxillary first molar.

The data collected from patient records were analysed. The collected data from the prosthodontic status of the patient record was then tabulated in excel and then imported into SPSS software. Incomplete data was verified with the concerned department or patient or excluded from the study. The collected data included age, gender, tooth involved, treatment suggestion and treatment were done. A statistical test was done using a chi-square test with SPSS by IBM. Independent variables were included oral habits and systemic condition of the participants, whereas the dependent variables included the age and missing maxillary first molar. All of these were analysed using correlation and association.

Figure 1: Represents the association of the total number of participants based on gender and age group. $X$ axis represents the age group of the participants and $Y$ axis represents the number of participants in terms of percentage. Study population among the age group of 35-43 yrs (58.9\%) highest among the patients with missing maxillary first molar, it also shows the predominance of females $(69.2 \%)$ denoted by 'blue' than Males $(\mathbf{3 0 . 8 \%})$ denoted by 'red', however it is statistically insignificant with a $p$ value $>0.05$. Therefore, according to the graph female participants had more missing maxillary first molars than males. (Pearson Chi Square: 0.251 , df: 1 , p value: 6.16 )

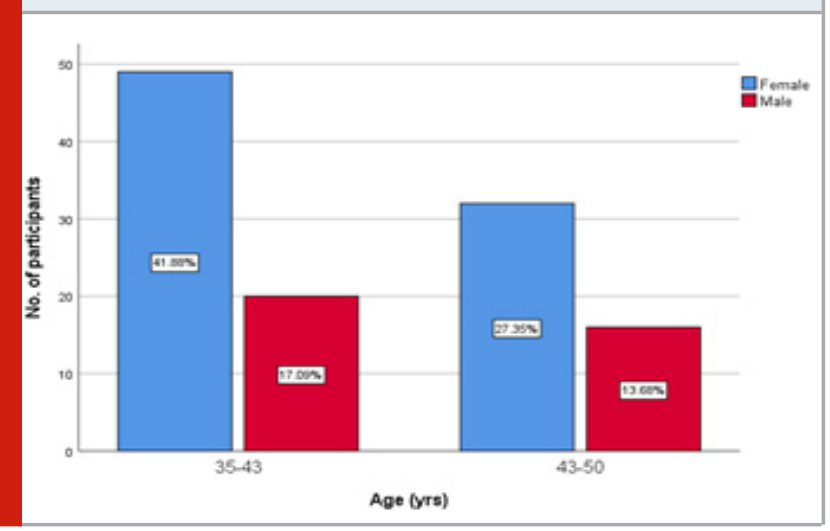

\section{RESULTS AND DISCUSSION}

A total of 117 participants were involved with the missing maxillary molar. Among them $69.2 \%$ were females and $30.8 \%$ were males. The study sample includes the participants under the age group of $35-50$ years. The prevalence of loss of molar was the highest among the age group of $35-43$ years $(58.9 \%)$ as seen in (Figure1). The prevalence of loss of missing maxillary first molar increases as the age increases. Statistical analysis of data demonstrates that the majority of edentates involved one single tooth in 
the maxillary arch $(36.7 \%)$ and edentulousness of both the maxillary first molars constituted $26.6 \%$ (Figure 2). From the total of edentulous area or the edentation, $34.2 \%$ were restored using fixed partial dentures. Majority of the participants did not opt for any treatment $(65.8 \%)$ due to various reasons like their economic status, willingness towards the treatment and their ability to afford (Figure 3 ). The number of patients who had received fixed partial dentures as their prosthetic treatment is $42(35.9 \%)$ (Figure 3 ) with a statistically significant $p$ value of $<0.05$ (Table 1).

Figure 2: Represents the association of the missing maxillary first molar according to the age group of the study population. $\mathrm{X}$ axis represents the age group of the study population and $\mathrm{Y}$ axis represents the number of participants in terms of percentage. $36.7 \%$ of the population predominantly had single missing right maxillary first molars denoted by 'blue' and single missing left maxillary first molars denoted by 'green', whereas missing maxillary first molars on both the quadrants denoted by 'red' summed up to $26.6 \%$. According to this graph, Single missing maxillary first molar was more predominant than the bilaterally missing maxillary first molar. (Pearson Chi Square- 0.286, df- 2, $\mathrm{p}$ value- $0.867(>0.05))$.

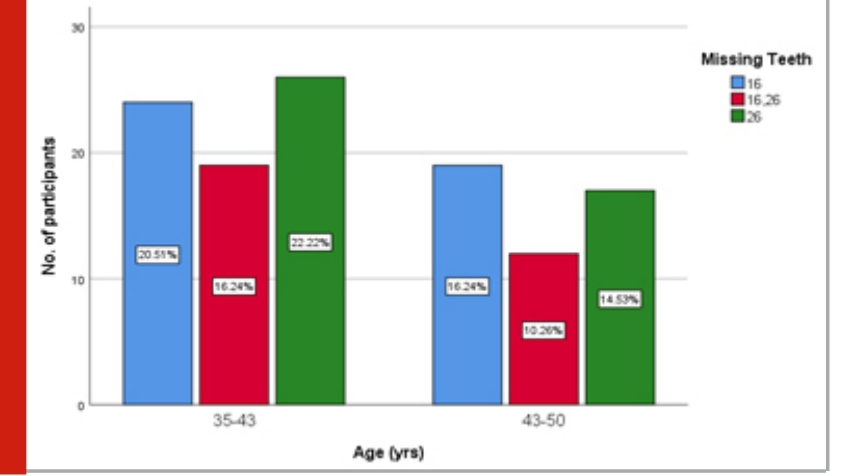

Table 1. Association of treatment opted by the patient according to the missing first maxillary molar (chi-square test)

\begin{tabular}{|l|c|c|c|}
\hline Chi-Square Tests & Value & df & $\begin{array}{c}\text { Asymptotic } \\
\text { Significance } \\
\text { (2-sided) }\end{array}$ \\
Pearson Chi-Square & $6.311 \mathrm{a}$ & 2 & .043 \\
\hline Likelihood Ratio & 6.464 & 2 & .039 \\
\hline N of Valid Cases & 117 & & \\
\hline
\end{tabular}

a. 0 cells $(.0 \%)$ have expected count less than 5 . The minimum expected count is 10.60 .

In accordance to the age group, $35.3 \%$ of the patients among the age group of 35 - 43 years opted for fixed partial denture as their treatment and among the age group of 43 - 50 years, $34.7 \%$ of them opted for fixed partial denture as a treatment option for the restoration of edentates. In comparison of both the age groups, there is not much significance on the
Figure 3: Represents the frequency distribution of the fixed partial denture (FPD) as a treatment option for missing maxillary first molar. $X$ axis represents the missing teeth and $\mathrm{Y}$ axis represents the number of participants in terms of percentage. Only $34.2 \%$ of the participants opted FPD (denoted by 'blue') as a treatment choice for the restoration of the edentations. Chi square test was done and association was found to be statistically significant. However according to this graph, participants opting FPD as a treatment plan were lesser than participants opting various other treatments for restoration of edentations. (Pearson Chi Square- 6.3, df- 2, p value- $0.043(<0.05)$.

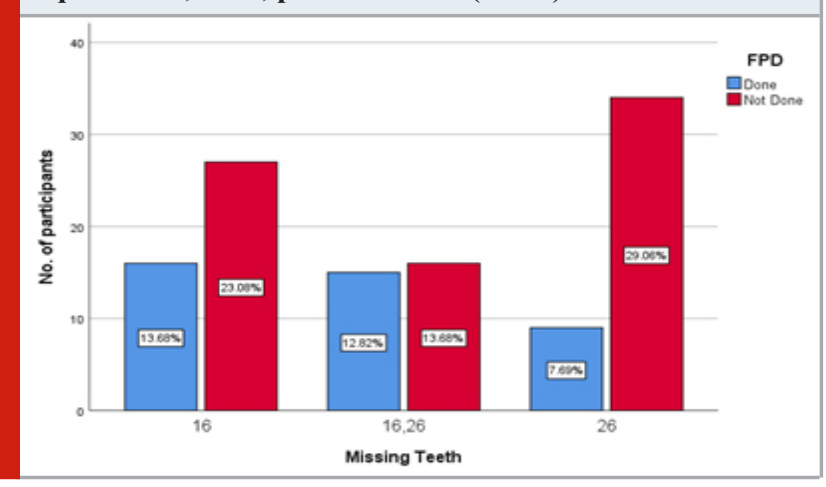

treatment or prosthesis opted to restore the edentations, which is the fixed partial denture (Figure 4). The present study showed that out of 117 participants with missing maxillary first molars only $35.9 \%$ of them opted fixed partial denture as a treatment option. The maximum number of cases seen in age groups of $35-43$ years $(58.1 \%)$. This could be due to the increased risk of periodontal pathologies as the age advances and due to increase in progression of caries. In a study conducted by Vignarajah Showed those various reasons for permanent tooth being edentate was found to have a greater prevalence of loss of tooth in the age 40 years and above (Vignarajah, 1993; Scrascia et al., 2020; Fareen et al., 2021).

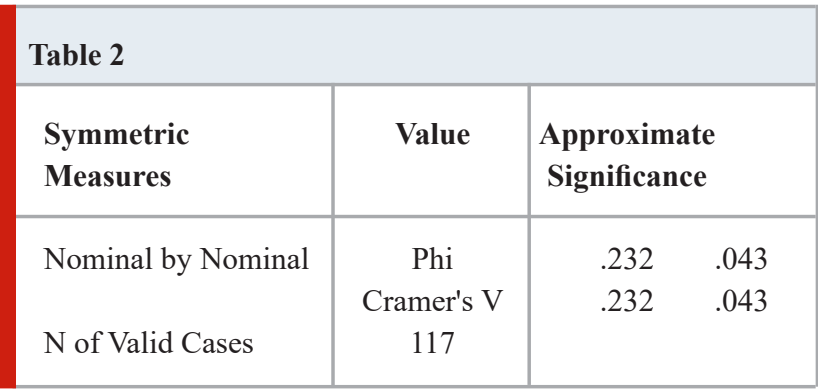

Upadhyay et al., stated in his study that a steady rise in the loss of missing first molars was seen from the mid of 3 rd to 4 th decade $(47.39 \%)$ and the probability to lose the molar increased and reached $68 \%$ as the age increases by 6th - 7th decade (Upadhyaya and Humagain, 2009). Also in contradiction, Hedge et al., shows the maximum loss of first maxillary molars among the age group of $56-65$ years $(23.3 \%)$. This increase is due to the progression of caries coupled with periodontal disease as the age increases. Among the participants involved in this study, significantly $64.7 \%$ under the age group of 35 - 43 years and $65.3 \%$ 
under the age group of 43 - 50 years have not opted fixed dental prosthesis as the treatment option. These patients either go with temporary partial dentures due to their socio-economic status or as they do not want to disturb the morphology of the tooth which is needed to be used as the abutments. Whereas others opted for Dental implants being the better options for the restoration of edentations (Ashok and Suvitha, 2016; Vijayalakshmi and Ganapathy, 2016; Ranganathan et al., 2017; Hegde et al., 2018; Scrascia et al., 2020; Cimõeset al., 2021).

Figure 4: Represents the distribution of fixed partial denture (FPD) as a treatment option based on the age group of the participants. $X$ axis represents the age group of the participants and $Y$ axis represents the number of participants in terms of percentage. $20.51 \%$ and $13.68 \%$ of the participants underwent FPD (denoted by 'blue') as the prosthesis for restoration of edentations among the age group of 35-43 years and 43-50 years respectively with an insignificant $p$ value $>\mathbf{0 . 0 5}$. According to this graph, participants opting FPD as a treatment plan were lesser among both the age groups than participants opting various other treatments for restoration of edentations. (Pearson Chi Square- 0.026, df- 2, p value- 0.871 ( $>0.05)$.

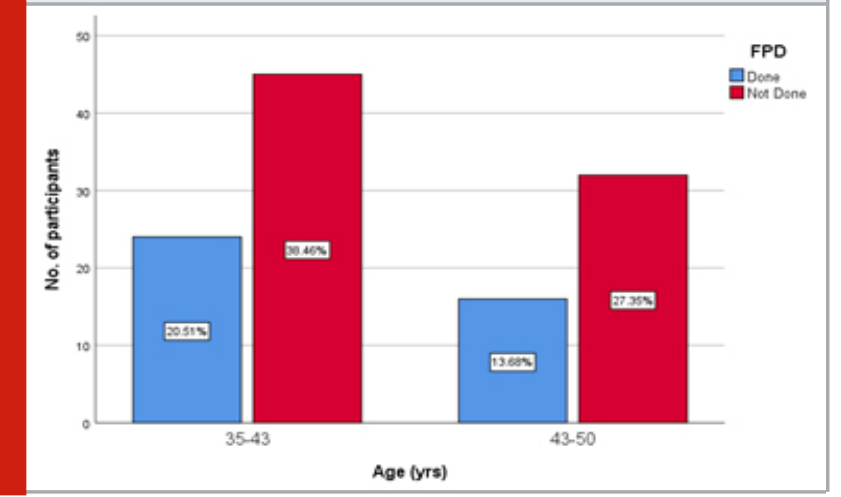

The multidimensional relationship between behavioral risk factors, socioeconomic status and tooth decay as a major cause of tooth extraction is well established. The choice of prosthesis to be used for the restoration of edentations are decided by the patient in accordance to their economic status. Families that are economically disadvantaged have lesser access to dental care and to the use of other health care services, hence they tend to cause the least or they are unable to undergo regular dental visits for the maintenance of their oral hygiene. The socio-economic status is inversely associated with the presence of edentations in the oral cavity of the patients. The subjects which are in medium and low levels are under higher risks of becoming edentulous. The high concern about the consequences and management of edentation is mainly associated with high socio-economical level. The main reasons for neglecting the edentation is due to the lack of awareness and the inadequate financial constraints of the patient (Khazaei et al., 2012; Venugopalan et al., 2014; Patturaja and Pradeep, 2016; Subashri and Uma Maheshwari, 2016; Subasree et al., 2016; Basha et al., 2018; Manicone et al., 2021).
The present study shows that the prevalence of missing maxillary first molars is commonly seen in female patients $(62.2 \%)$ than males. In contradiction, study by Hedge et al., showed that $59 \%$ of the male participants with higher prevalence of missing maxillary first molar than the female (41\%). Locker et al., suggested in their study on the incidence of and risk factors for tooth loss found that males had more percentage of losing one or more teeth than females. This could be due to adverse habits like smoking, alcohol, tobacco chewing in males(Ajay et al., 2017).Our institution is passionate about high quality evidence based research and has excelled in various fields (Pc et al., 2018; Hegde et al., 2018; Ramesh et al., 2018; Ezhilarasan et al., 2019; Ramadurai et al., 2019; Sridharan et al., 2019; Vijayashree, 2019; Mathew et al., 2020). Limitations of the study conducted includes the reduction or the availability of the data, the unequal distribution of cases and the unavailability of area specific data. Hence, the results of this study must be interpreted within the limitations of this study and further cohort studies must be done including larger data. Such study should also include certain other parameters like the reasons for extraction, the patients' socio-economic status and their diet.

\section{CONCLUSION}

Within the limits of this study, the highest predominance of missing maxillary first molars was among the females than the males. With an increase in the prevalence of missing maxillary first molars among the age group of $35-43$ years, $35.9 \%$ of the participants chose fixed partial denture prosthesis as the treatment choice for the restoration of their edentates.

Conflict of Interest: The authors declare that they have no conflicts of interest.

\section{REFERENCES}

Ajay, R. et al. (2017). Effect of surface modifications on the retention of cement-retained implant crowns under fatigue loads: An In vitro study. Journal of Pharmacy And Bioallied Sciences, p. 154. doi: 10.4103/jpbs. jpbs_146_17.

Angelillo, I. F., Nobile, C. G. and Pavia, M. (1996). Survey of reasons for extraction of permanent teeth in Italy. Community dentistry and oral epidemiology, 24(5), pp. 336-340.

Ariga, P. et al. (2018). Determination of Correlation of Width of Maxillary Anterior Teeth using Extraoral and Intraoral Factors in Indian Population: A Systematic Review. World Journal of Dentistry, pp. 68-75. doi: 10.5005/jp-journals-10015-1509.

Artun, J. and Thalib, L. (2011). Mesial migration and loss of first molars among young adolescents in Kuwait. Community dental health, 28(2), pp. 154-159.

Ashok, V. and Suvitha, S. (2016). Awareness of all ceramic restoration in rural population. Research Journal of Pharmacy and Technology, p. 1691. doi: 10.5958/0974360x.2016.00340.1.

Basha, F. Y. S., Ganapathy, D. and Venugopalan, S. 
(2018). Oral Hygiene Status among Pregnant Women. Research Journal of Pharmacy and Technology, p. 3099. doi: 10.5958/0974-360x.2018.00569.3.

Çağlaroğlu, M., Kilic, N. and Erdem, A. (2008). Effects of early unilateral first molar extraction on skeletal asymmetry. American journal of orthodontics and dentofacial orthopedics: official publication of the American Association of Orthodontists, its constituent societies, and the American Board of Orthodontics, 134(2), pp. 270-275.

Cimões, R., Pinho, R.C.M., GURGEL, B.C.D.V., Borges, S.B., MARCANTONIO JÚNIOR, E., Marcantonio, C.C., MELO, M.A.R.D.C., Piattelli, A. and Shibli, J.A., (2021). Impact of tooth loss due to periodontal disease on the prognosis of rehabilitation. Brazilian Oral Research, 35. Duraisamy, R. et al. (2019). Compatibility of Nonoriginal Abutments with Implants: Evaluation of Microgap at the Implant-Abutment Interface, With Original and Nonoriginal Abutments. Implant dentistry, 28(3), pp. 289-295.

Ezhilarasan, D., Apoorva, V. S. and Ashok Vardhan, N. (2019). Syzygium cumini extract induced reactive oxygen species-mediated apoptosis in human oral squamous carcinoma cells. Journal of oral pathology \& medicine: official publication of the International Association of Oral Pathologists and the American Academy of Oral Pathology, 48(2), pp. 115-121.

Fareen, H.F., Ashok, V. and Rengalakshmi, S., (2021). Prevalence in Replacement of Missing Mandibular First Molar among Young Adult. Annals of the Romanian Society for Cell Biology, pp.6111-6123.

Ganapathy, D. et al. (2016). Effect of Resin Bonded Luting Agents Influencing Marginal Discrepancy in All Ceramic Complete Veneer Crowns. Journal of clinical and diagnostic research: JCDR, 10(12), pp. ZC67-ZC70.

Ganapathy, D. M., Kannan, A. and Venugopalan, S. (2017).

Effect of Coated Surfaces influencing Screw Loosening in Implants: A Systematic Review and Meta-analysis. World Journal of Dentistry, pp. 496-502. doi: 10.5005/ jp-journals-10015-1493.

Gheena, S. and Ezhilarasan, D. (2019). Syringic acid triggers reactive oxygen species-mediated cytotoxicity in HepG2 cells. Human \& experimental toxicology, 38(6), pp. 694-702.

Haddad, I. et al. (1999). Reasons for extraction of permanent teeth in Jordan. International dental journal, 49(6), pp. 343-346.

Hegde, M. N., Mrinalini and Shetty, N. (2018). Prevalence of Root Caries in South Canara Population. Journal of Advances in Medicine and Medical Research, pp. 1-7. doi: 10.9734/jammr/2018/44638.

Hegde, M. N. and Ragavendran, N. (2012). Prevalance of missing first molar on South Indian population--A retrospective study. IJRD, 1(1), pp. 25-29.

Jose, J., Ajitha and Subbaiyan, H. (2020). Different treatment modalities followed by dental practitioners for Ellis class 2 fracture - A questionnaire-based survey. The open dentistry journal, 14(1), pp. 59-65.

Jyothi, S. et al. (2017). Periodontal health status of three different groups wearing temporary partial denture. Research Journal of Pharmacy and Technology, 10(12), pp. 4339-4342.

Kannan, A. and Venugopalan, S. (2018). A systematic review on the effect of use of impregnated retraction cords on gingiva. Research Journal of Pharmacy and Technology, p. 2121. doi: 10.5958/0974-360x.2018.00393.1.

Ke, Y. et al. (2019). Photosynthesized gold nanoparticles from Catharanthus roseus induces caspase-mediated apoptosis in cervical cancer cells (HeLa). Artificial cells, nanomedicine, and biotechnology, 47(1), pp. 19381946.

Khazaei, S. et al. (2012). Edentulism and Tooth Loss in Iran: SEPAHAN Systematic Review No. 6. International journal of preventive medicine, 3(Suppl 1), pp. S42-7.

Krishnaswamy, H. et al. (2020). Investigation of air conditioning temperature variation by modifying the structure of passenger car using computational fluid dynamics. Thermal science, 24(1 Part B), pp. 495-498.

Lacarbonara, M., Cazzolla, A.P., Lacarbonara, V., Lo Muzio, L., Ciavarella, D., Testa, N.F., Crincoli, V., Di Venere, D., De Franco, A., Tripodi, D. and Grassi, F.R., (2021). Prosthetic rehabilitation of maxillary lateral incisors agenesis using dental mini-implants: a multicenter 10-year follow-up. Clinical Oral Investigations, pp.1-12. Malli Sureshbabu, N. et al. (2019). Concentrated Growth Factors as an Ingenious Biomaterial in Regeneration of Bony Defects after Periapical Surgery: A Report of Two Cases. Case reports in dentistry, 2019, p. 7046203.

Manicone, P.F., De Angelis, P., Rella, E., Papetti, L. and D'Addona, A., (2021). Proximal Contact Loss in Implant-Supported Restorations: A Systematic Review and Meta-Analysis of Prevalence. Journal of Prosthodontics.

Mathew, M. G. et al. (2020). Evaluation of adhesion of Streptococcus mutans, plaque accumulation on zirconia and stainless steel crowns, and surrounding gingival inflammation in primary. Clinical oral investigations. Available at: https://link.springer.com/article/10.1007/ s00784-020-03204-9.

Mehta, M. et al. (2019). Oligonucleotide therapy: An emerging focus area for drug delivery in chronic inflammatory respiratory diseases. Chemico-biological interactions, 308, pp. 206-215.

Muthukrishnan, S. et al. (2020). Support vector machine for modelling and simulation of heat exchangers. Thermal science, 24(1 Part B), pp. 499-503.

Patturaja, K. and Pradeep, D. (2016). Awareness of Basic Dental Procedure among General Population. Research Journal of Pharmacy and Technology, p. 1349. doi: 10.5958/0974-360x.2016.00258.4.

Pc, J., Marimuthu, T. and Devadoss, P. (2018). Prevalence and measurement of anterior loop of the mandibular canal using CBCT: A cross sectional study. Clinical implant dentistry and related research. Available at: https:// 
europepmc.org/article/med/29624863.

Ramadurai, N. et al. (2019). Effectiveness of $2 \%$ Articaine as an anesthetic agent in children: randomized controlled trial. Clinical oral investigations, 23(9), pp. 3543-3550.

Ramesh, A. et al. (2018). Comparative estimation of sulfiredoxin levels between chronic periodontitis and healthy patients - A case-control study. Journal of periodontology, 89(10), pp. 1241-1248.

Ranganathan, H., Ganapathy, D. M. and Jain, A. R. (2017). Cervical and Incisal Marginal Discrepancy in Ceramic Laminate Veneering Materials: A SEM Analysis. Contemporary clinical dentistry, 8(2), pp. 272-278.

Rezaie, M. et al. (2018). A Radiographic Evaluation of Missing of Permanent First Molars in a Group of Iranian Children and Adults: A Retrospective Study. International journal of dentistry, 2018, p. 5253965.

Samuel, M. S. et al. (2019). Efficient removal of Chromium (VI) from aqueous solution using chitosan grafted graphene oxide (CS-GO) nanocomposite. International journal of biological macromolecules, 121, pp. 285-292. Samuel, S. R., Acharya, S. and Rao, J. C. (2020). School Interventions-based Prevention of Early-Childhood Caries among 3-5-year-old children from very low socioeconomic status: Two-year randomized trial. Journal of public health dentistry, 80(1), pp. 51-60.

Sathish, T. and Karthick, S. (2020). Wear behaviour analysis on aluminium alloy 7050 with reinforced $\mathrm{SiC}$ through taguchi approach. Journal of Japan Research Institute for Advanced Copper-Base Materials and Technologies, 9(3), pp. 3481-3487.

Scrascia, R. et al. (2020). Implant-Supported Prosthesis for Edentulous Patient Rehabilitation. From Temporary Prosthesis to Definitive with a New Protocol: A Single Case Report. Prosthesis, pp. 10-24. doi: 10.3390/ prosthesis2010002.

Sharma, P. et al. (2019). Emerging trends in the novel drug delivery approaches for the treatment of lung cancer. Chemico-biological interactions, 309, p. 108720.

Sridharan, G. et al. (2019). Evaluation of salivary metabolomics in oral leukoplakia and oral squamous cell carcinoma. Journal of oral pathology \& medicine: official publication of the International Association of Oral Pathologists and the American Academy of Oral Pathology, 48(4), pp. 299-306.

Subashri,A. and Uma Maheshwari, T. N. (2016). Knowledge and attitude of oral hygiene practice among dental students. Research Journal of Pharmacy and Technology, p. 1840. doi: 10.5958/0974-360x.2016.00375.9.
Subasree, S., Murthykumar, K. and Dhanraj (2016). Effect of Aloe Vera in Oral Health-A Review. Research Journal of Pharmacy and Technology, p. 609. doi: 10.5958/0974360x.2016.00116.5.

Upadhyaya, C. and Humagain, M. (2009). The pattern of tooth loss due to dental caries and periodontal disease among patients attending dental department (OPD), Dhulikhel Hospital, Kathmandu University Teaching Hospital (KUTH), Nepal. Kathmandu University medical journal, 7(25), pp. 59-62.

Varghese, S. S., Ramesh, A. and Veeraiyan, D. N. (2019). Blended Module-Based Teaching in Biostatistics and Research Methodology: A Retrospective Study with Postgraduate Dental Students. Journal of dental education, 83(4), pp. 445-450.

Venugopalan, S. et al. (2014). Magnetically retained silicone facial prosthesis. Nigerian journal of clinical practice, 17(2), pp. 260-264.

Venu, H., Raju, V. D. and Subramani, L. (2019). Combined effect of influence of nano additives, combustion chamber geometry and injection timing in a DI diesel engine fuelled with ternary (diesel-biodiesel-ethanol) blends. Energy, 174, pp. 386-406.

Venu, H., Subramani, L. and Raju, V. D. (2019). Emission reduction in a DI diesel engine using exhaust gas recirculation (EGR) of palm biodiesel blended with $\mathrm{TiO} 2$ nano additives. Renewable Energy, 140, pp. 245-263.

Vignarajah, S. (1993). Various reasons for permanent tooth extractions in a Caribbean population-Antigua. International dental journal, 43(3), pp. 207-212.

Vignesh, R. et al. (2019). Management of Complicated Crown-Root Fracture by Extra-Oral Fragment Reattachment and Intentional Reimplantation with 2 Years Review. Contemporary clinical dentistry, 10(2), pp. 397-401.

Vijayakumar Jain, S. et al. (2019). Evaluation of ThreeDimensional Changes in Pharyngeal Airway Following Isolated Lefort One Osteotomy for the Correction of Vertical Maxillary Excess: A Prospective Study. Journal of maxillofacial and oral surgery, 18(1), pp. 139-146.

Vijayalakshmi, B. and Ganapathy, D. (2016). Medical management of cellulitis. Research Journal of Pharmacy and Technology, p. 2067. doi: 10.5958/0974360x.2016.00422.4.

Vijayashree P., J. (2019). In silico validation of the non-antibiotic drugs acetaminophen and ibuprofen as antibacterial agents against red complex pathogens. Journal of periodontology, 90(12), pp. 1441-1448. 